Original article

\title{
Oncology nurses' knowledge about exploring chemotherapy related - Extravasation care: A cross-sectional study
}

\author{
Loai Abu Sharour \\ Faculty of Nursing, AL-Zaytoonah University of Jordan, P.O. Box, 130 Amman, 11733, Jordan
}

\section{A R T I C L E I N F O}

\section{Keywords:}

Chemotherapy extravasation

Oncology nurses

Knowledge

Practices. ESMO

EONS

\begin{abstract}
A B S T R A C T
Introduction: can cause significant tissue damage; alter limb function, pain and decreasing quality of life. Nurses play a significant role in the prevention, identification and follow-up of the complications.

Objectives: This study was conducted to evaluate the oncology nurses' knowledge about chemotherapy related extravasation injuries, risk factors, preventive measures, and management practices.

Methods: A descriptive cross-sectional design with a convenience sample was used. A sample of 110 oncology nurses completed the knowledge test. European Society for Medical Oncology (ESMO) - European Oncology Nursing Society (EONS) management of chemotherapy extravasation Clinical practice guidelines were used to develop the knowledge test.

Results: The oncology nurses' knowledge of chemotherapy related-extravasation's definition and signs and symptoms was satisfactory. However, knowledge about risk factors was limited. Generally, the results showed that high percentage of the participants had correct information regarding the procedure domain. However, knowledge deficit regarding site of insertion, and cannula characteristics were reported. The results showed that there was knowledge deficit among the participants regarding all specific treatment practices.

Conclusions: The current study provides a baseline data about oncology nurses knowledge and practice regarding chemotherapy related-extravasation care. Continues education, seminars, and workshops should be conducted for oncology nurses to increase their knowledge and strengthen their competencies.
\end{abstract}

\section{Introduction}

Cancer is one of main health problem and life threatening disease in the world. The number of patients diagnosed with cancer is increasing, more than 14 million patient were diagnosed with cancer, these numbers are expected to increase at least by $70 \%$ in the next ten years. ${ }^{1}$ For example, in Jordan, cancer is a second leading cause of morbidity and mortality, and the number of new cases was increased in the last ten years and expected to increase also. ${ }^{2}$ Once the diagnosis is confirmed, different treatment modalities such chemotherapy, surgery, and radiotherapy might be utilized depending on the type and stage of cancer. ${ }^{3}$

Chemotherapy administration is the principle and most common type of treatment modalities. More than one million infusions of chemotherapy were performed each day worldwide. ${ }^{4}$ Regardless the powerful effect on chemotherapy treatment, it may cause many side effects that might affect the treatment plan, prognosis, and response to the treatment such as chemotherapy related-extravasation. ${ }^{5}$

Extravasation is defined as one of the complications related to cytotoxic drugs such as chemotherapy. It is defined as accidental damage of subcutaneous tissue or perivascular space related to leakage of the cytotoxic drug. ${ }^{6}$ The severity of damage depends on the amount and type of leaked drug, time, and toxicity. ${ }^{7}$ Because of shortage in reporting and registration of chemotherapy extravasation events; the incidence of extravasation varies. It ranges from $1 \%$ to $6 \%$ worldwide. ${ }^{8}$ In Jordan, the incidence of chemotherapy extravasation is unavailable because of absence of reporting system.

Several risk factors are associated with chemotherapy related - extravasation. Patient related factors such as age, fragile vein, obesity, lymphedema, peripheral vascular dieses, diabetes mellitus, and impaired sensory perception. Type of chemotherapy drug, device-related factors such as metal needles, large gage catheter, location of insertion, and health professional -related factors such as cannulation technique, lack of experience, lack of knowledge, lack of training, and nonadherence to the guidelines of chemotherapy administrations. ${ }^{9}$

Numbers of signs and symptoms associated with chemotherapy extravasation such as redness, swelling, pain, necrosis, burning sensation, and discomfort. In addition, resistance during drug infusion, slow infusion, and decrease blood return may be considered as predictors for extravasation. $^{10}$

In order to prevent, early detect, and minimize the chemotherapy

E-mail addresses: Loai.S@zuj.edu.jo, luay_shahrour@yahoo.com, Loai.S@zuj.edu.jo. 
related-extravasation; all oncology nurses (as bedside care providers) should be knowledgeable about extravasation risk factors, managements, and preventive measures. Moreover, continuous training of oncology nurses about recent evidence-based guidelines regarding chemotherapy handling is recommended.

Continue education and training among oncology nurses remains the backbone of safe administration of chemotherapy and highlights the importance of being preventive instead of reactive to the side effects such as extravasation. ${ }^{11}$ In order to develop a structured educational program to increase nurses' knowledge about extravasation, evaluation of their knowledge is the first step. Based on the results, the educational program's content will be developed. Indeed, there is limited literature conducted to evaluate the oncology nurses' knowledge about extravasation risk factors, management, preventive measures, and caring in the region.

\section{Methods}

\subsection{Study design and purpose}

A descriptive cross-sectional design was used to evaluate nurses' knowledge about chemotherapy related-extravasation Injuries: risk factors, preventive measures, and management.

\subsection{Setting and procedure}

A convenience sampling technique was used to recruit participants from oncology units including surgical, medical, haematological, paediatric, and adult clinics. Sample of 120 participants was estimated using power analysis. ${ }^{12}$ After ethical approval was granted, the research assistant explained the study purpose and methods to the unit mangers and in charge nurses to approach the eligible participants. The participants who met the inclusion criteria including those working with cancer patients directly, administer chemotherapy, and worked with patient with extravasation. Once the participants identified and greed to participate, a compromising file including the information sheet, consent form, and study survey was given to them by the researcher assistant, and collected again once they finished. A sample of 140 oncology nurses who met the criteria was invited to participate, 110 participants participated with response rate $78.5 \%$. Thirty participants declined participation without reasoning.

\subsection{Instruments and procedures}

A demographic data was collected. Data related to the participants' age, years of experience, educational level, job title, and hours of education about extravasation pre-graduation and continued education at the hospital regarding extravasation. Demographic sheet was developed by the researcher based on the previous literature.

\subsection{Knowledge test}

Knowledge test was developed by the author to assess the oncology nurses' knowledge about chemotherapy Extravasation Injuries: risk factors, preventive measures, and management. Fifty multiple choice questions with four choices were developed by the author. The questions tested the comprehension, understanding, application, and analysis levels of the participants. Related textbooks, previous literature, and European Society for Medical Oncology (ESMO)- European Oncology Nursing Society (EONS) management of chemotherapy extravasation Clinical practice guidelines were used to develop the knowledge test. ${ }^{13}$ The test included questions related to definition (2 questions), signs and symptoms (5 questions), risk factors (15 questions), preventive measures (13 questions), management (15 questions). The total score of the test was 100 points (each question weighted two points). The cutoff score was 60 points (passing score for nursing degree). Score below $60 \%$ is considered unsatisfactory, between 60 and 74.9 was considered acceptable, score between 75 and 84 was considered good, and above 85 was considered excellent. The average time to complete the test was $65 \mathrm{~min}$. Knowledge test was developed by the author in consultation with two professional and experts in academic and clinical fields (one was associate professor in nursing and one was clinical nurse specialist/oncology). Face and content validity were checked prior implementation. Preliminary reliability was measured also. A pilot study was conducted to evaluate validity, reliability, and applicability of the test before using it in the large study. Sample of ten participants completed the test; the results showed the test was reliable with cronbach's alpha 0.83 .

\subsection{Statistical analyses}

Statistical Package for the Social Science (SPSS version 23.0) was used to analyse the data. Descriptive analyses included mean, standard deviation and frequencies was used.

\section{Results}

\subsection{Sample characteristics}

A sample of 110 oncology nurses participated in the study; 78 were males $(70.9 \%)$ and 32 were female (29.1\%). Mean age was 26.4 (SD 5.24 ) years. The results showed that the majority of participants held a bachelor's degree in nursing (91.9\%). Finally, 94.6\% (104) of the participants reported a desire to attend a structured educational program about chemotherapy extravasation. Table 1 details these results.

\section{Knowledge results}

\subsection{Knowledge of definition, signs and symptoms, and risk factors}

The nurses' knowledge about the extravasation definition, signs and symptoms, and risk factors was assessed using twenty-two statements derived from the related textbooks, previous literature, and European Society for Medical Oncology (ESMO)- European Oncology Nursing

Table 1

Demographic characteristics of the participants $(\mathrm{N}=110)$.

\begin{tabular}{|c|c|c|c|}
\hline Variable & Number $(\mathrm{N})$ & Percentage (\%) & $\begin{array}{l}\text { Mean } \\
\text { (Standard } \\
\text { Deviation }\end{array}$ \\
\hline Age & & & $25.8(4.24)$ \\
\hline \multicolumn{4}{|l|}{ Gender } \\
\hline Male & 78 & 70.9 & \\
\hline Female & 32 & 29.1 & \\
\hline \multicolumn{4}{|l|}{ Job Tittle } \\
\hline Practical Nurse & 6 & 5.4 & \\
\hline Registered Nurse & 91 & 82.8 & \\
\hline In charge Nurse & 10 & 9.1 & \\
\hline Unit Manager & 3 & 2.7 & \\
\hline \multicolumn{4}{|l|}{ level of academic qualification } \\
\hline Diploma & 6 & 5.4 & \\
\hline Bachler & 101 & 91.9 & \\
\hline Postgraduate & 3 & 2.7 & \\
\hline $\begin{array}{l}\text { Received hours of education } \\
\text { about extravasation pre- } \\
\text { graduation }\end{array}$ & & & 1.1 (SD 0.40) \\
\hline $\begin{array}{l}\text { Experience in oncology field } \\
\text { (years) }\end{array}$ & & & 2.3 (SD 1.10) \\
\hline \multicolumn{4}{|c|}{ Desire to attend continue education program regarding extravasation at hospital } \\
\hline Yes & 104 & 94.6 & \\
\hline No Need & 6 & 5.4 & \\
\hline \multicolumn{4}{|c|}{ Did you receive continue education program regarding extravasation at hospital } \\
\hline No & 104 & 94.6 & \\
\hline Yes & 6 & 5.4 & \\
\hline
\end{tabular}


Table 2

Nurses' Knowledge of definition, signs and symptoms, and risk Factors ( $\mathrm{N}=110)$.

\begin{tabular}{|c|c|c|c|}
\hline & Factor & $\begin{array}{l}\text { Correct answer } \\
\mathrm{N}(\%)\end{array}$ & $\begin{array}{l}\text { Wrong answer } \\
\mathrm{N}(\%)\end{array}$ \\
\hline \multirow[t]{2}{*}{ Definition } & Any liquid leaks into the surrounding tissue & $102(92.7)$ & $8(7.3)$ \\
\hline & $\begin{array}{l}\text { Infiltration of chemotherapy into the subcutaneous or subdermal tissues surrounding the intravenous or intra-arterial } \\
\text { administration site }\end{array}$ & $102(92.7)$ & $8(7.3)$ \\
\hline \multirow[t]{4}{*}{ Signs and symptoms } & Tingling, burning, discomfort/pain swelling, erythema, and/or blistering & $100(90.9)$ & $10(9.1)$ \\
\hline & Marked induration, often brownish, lasting for days to months with skin atrophy & $60(54.5)$ & $50(45.5)$ \\
\hline & Invasive ulceration which may occur after $1-4$ weeks & 45 (40.9) & $65(59.1)$ \\
\hline & Increased infusion resistance & $90(81.8)$ & $20(18.2)$ \\
\hline \multirow[t]{16}{*}{ Risk factors } & Small fragile, and mobile veins, Hard veins related to previous chemotherapy courses & $80(72.2)$ & $30(27.8)$ \\
\hline & Obesity & $30(27.8)$ & $80(72.2)$ \\
\hline & peripheral vascular disease, Raynaud & $35(31.8)$ & $75(68.2)$ \\
\hline & Syndrome, diabetes, lymphedema, and superior cava syndrome. & & \\
\hline & coagulation abnormalities & $40(36.3)$ & $70(63.7)$ \\
\hline & Sensory deficits & $42(38.1)$ & $68(61.9)$ \\
\hline & Communication difficulties/lack of early reporting of the sings. & $50(45.5)$ & $60(54.5)$ \\
\hline & Prolonged infusion & $20(18.2)$ & $90(81.8)$ \\
\hline & Inexperienced staff & $90(81.8)$ & $20(18.2)$ \\
\hline & Poor cannula fixation and dressing & $70(63.7)$ & $40(36.3)$ \\
\hline & Central venous access devices poorly implanted. & $100(90.9)$ & $10(9.1)$ \\
\hline & Multiple attempts at cannulation & $90(81.8)$ & $20(18.2)$ \\
\hline & cannulation site & $30(27.8)$ & $80(72.2)$ \\
\hline & Bolus injections & $28(25.5)$ & $82(74.5)$ \\
\hline & High flow pressure & $40(36.3)$ & $70(63.7)$ \\
\hline & Choice of equipment (peripheral catheter choice, size, steel 'Butterfly' needle) & $35(31.8)$ & $75(68.2)$ \\
\hline
\end{tabular}

Society (EONS) management of chemotherapy extravasation Clinical practice guidelines. ${ }^{13}$ In general, the results showed that high percentage of the participants had correct definition of extravasation (102, $92.7 \%$ ). Around fifty percentages of the participants had correct information related to signs and symptoms specifically marked induration, often brownish, lasting for days to months with skin atrophy, and invasive ulceration which may occur after 1-4 weeks (45.5\%, and $59.1 \%$ respectively). Unsatisfactory level of knowledge related to some risk factors for extravasation such as obesity, coagulation abnormalities, prolonged infusion, and Bolus injections. Detailed results are presented in Table 2 .

\subsection{Knowledge of preventive strategies}

Nurses' knowledge regarding extravasation-preventive measures was assessed by using thirteen statements. ${ }^{13}$ Generally, the results showed that the high percentage of the participants had correct information regarding the procedure domain. However, knowledge deficit regarding site of insertion, and cannula characteristics were reported. Table 3 details these results.

\subsection{Knowledge of management practices}

The results for knowledge about chemotherapy extravasation management practices are presented in Table 4. Management practices were divided into three parts including initial measures (4 items), specific treatment ( 6 items), and general measures ( 5 items). The results showed that the majority of the participants had incorrect answer regarding initial measures practices such as withdraw the infusion equipment, but not the venous catheter (81.1\%). Alarmingly, the results showed that there was knowledge deficit among the participants regarding all specific treatment practices. Finally, the results showed that 95.5\% of the participants knew that they should raise the affected extremity over the height of the heart. However, their information about other general measures was limited.

\section{Discussion}

Nurses play an important role during chemotherapy administration including pre-and post-administration assessment, prevent and minimize the expected complications. Patient safety is the ultimate goal and part of daily nursing practices. In order to have safe environment and practice safely, it is crucial that the nurses have adequate level of knowledge and practice within recent evidence-based guidelines. ${ }^{14}$ This cross-sectional study was conducted to explore oncology nurses' knowledge about chemotherapy Extravasation Injuries: risk factors, preventive measures, and management.

The knowledge test was divided to three parts in the current study

Table 3

Nurses' knowledge of preventive strategies $(\mathrm{N}=110)$.

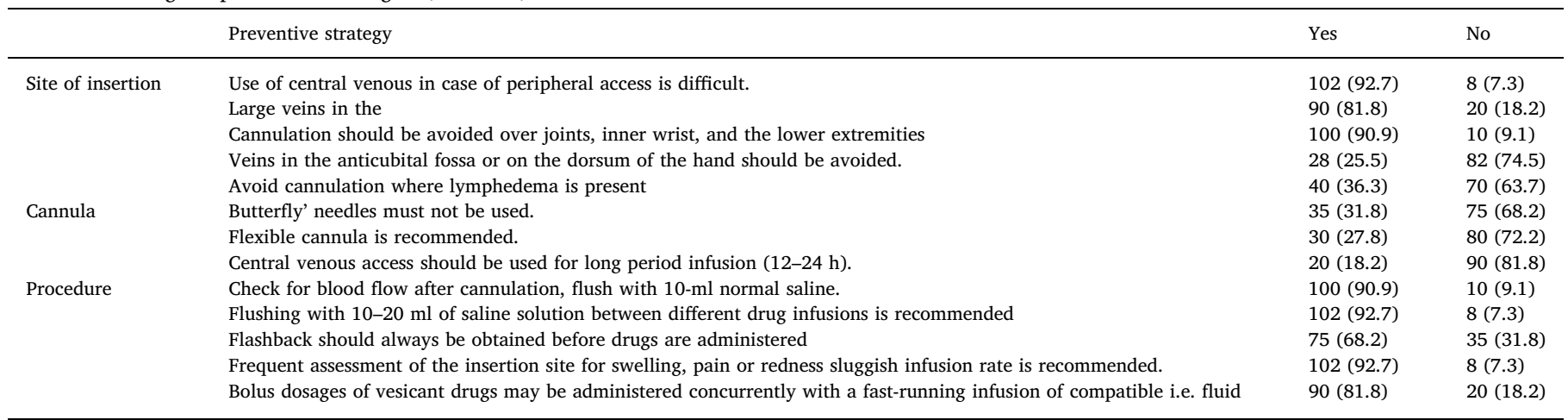


Table 4

Nurses' Knowledge of extravasation management guideline $(\mathrm{N}=110)$.

\begin{tabular}{|c|c|c|c|}
\hline & Management practice & Yes & No \\
\hline \multirow[t]{4}{*}{ Initial Measures } & Stop the drug infusion & $102(92.7)$ & $8(7.3)$ \\
\hline & Withdraw the infusion equipment, but not the venous catheter & $20(18.2)$ & $90(81.8)$ \\
\hline & Aspire $5-10 \mathrm{ml}$ of blood through the venous catheter to extract the maximum quantity of the extravasated drug & $30(27.8)$ & $80(72.2)$ \\
\hline & Withdraw the venous catheter & $35(31.8)$ & $75(68.2)$ \\
\hline \multirow[t]{10}{*}{ Specific Treatment } & $\begin{array}{l}\text { Amsacrine } \\
\text { - Apply topical DMSO 99\% onto double the affected area. Allow it to dry without covering it, and apply topical DMSO } 99 \% \\
\text { every } 6 \mathrm{~h} \text { for } 14 \text { days }\end{array}$ & $15(13.6)$ & $95(86.4)$ \\
\hline & Daunorubicin, doxorubicin, epirubicin, idarubicin, mitomycina, and mitoxantrone & $22(20)$ & $88(80)$ \\
\hline & $\begin{array}{l}\text { - Apply topical DMSO } 99 \% \text { onto double the affected area. Allow it to dry without covering it, and apply topical DMSO } 99 \% \\
\text { every } 6 \mathrm{~h} \text { for } 14 \text { days. } \\
\text { - Apply local cold for } 60 \mathrm{~min} \text {. Repeat every } 8 \mathrm{~h} \text { for three days. }\end{array}$ & $18(16.3)$ & $92(83.7)$ \\
\hline & Vinblastineb, vincristineb, vindesineb, and vinorelbineb & $27(24.5)$ & $83(75.5)$ \\
\hline & $\begin{array}{l}\text { - Administer six injections of } 150 \mathrm{IU}(0.5 \mathrm{ml}) \text { of SC hyaluronidase in the affected and surrounding area. } \\
\text { - Apply dry heat for } 30 \mathrm{~min} \text { after the injection of hyaluronidase }\end{array}$ & $12(10.9)$ & $98(90.1)$ \\
\hline & Cisplatin, clormetin, and dacarbazine & $8(7.3)$ & $102(92.7)$ \\
\hline & - Administer $2 \mathrm{ml}$ of SC sodium thiosulfate molar concentration of $1 / 6$ for every $\mathrm{mg}$ of extravasated drug, in several injections & $15(13.6)$ & $95(86.4)$ \\
\hline & $\begin{array}{l}\text { - Cisplatin: Administer thiosulfate only if cisplatin concentration is more than } 0.4 \mathrm{mg} / \mathrm{ml} \text { or if the extravasated volume is more } \\
\text { than } 20 \mathrm{ml} \text {. } \\
\text { - Dacarbazine: Administer thiosulfate only if persistent signs of extravasation are present or if the lesion progresses after } \\
12-24 \mathrm{~h} \text {. }\end{array}$ & $22(20)$ & $88(80)$ \\
\hline & Etoposideb, ifosfamide, and teniposideb & $27(24.5)$ & $83(75.5)$ \\
\hline & $\begin{array}{l}\text { - Administer six injections of } 150 \mathrm{IU}(0.5 \mathrm{ml}) \text { of SC hyaluronidase in the affected and surrounding area. } \\
\text { - Ifosfamide: Administer hyaluronidase only if persistent signs of extravasation are present or the lesion progresses after } 12-24 \mathrm{~h}\end{array}$ & $20(18.2)$ & $90(81.8)$ \\
\hline \multirow[t]{5}{*}{ General Measures } & Raise the affected extremity over the height of the heart & $105(95.5)$ & $5(4.5)$ \\
\hline & Do not apply pressure at the affected area. Avoid bandages & $75(68.2)$ & $35(31.8)$ \\
\hline & Gently apply common hygienic measures. Do not clean with detergent if tissue necrosis has occurred & $30(27.8)$ & $80(72.2)$ \\
\hline & Avoid exposure of the affected area to sunlight & $20(18.2)$ & $90(81.8)$ \\
\hline & Pharmacologic treatment with or without hot or cold treatment can be repeated if necessary after 12 and $24 \mathrm{~h}$. & $15(13.6)$ & $95(86.4)$ \\
\hline
\end{tabular}

including ${ }^{1}$ knowledge of definition, signs and symptoms, and risk factors, ${ }^{2}$ knowledge of preventive strategies, and ${ }^{3}$ knowledge of management practices. According to the first part, the results of the current study showed that nurses had satisfactory knowledge regarding definition of extravasation, fifty percent had correct knowledge about signs and symptoms, and alarmingly, unsatisfactory level of knowledge regarding many of risk factors was reported. These results could be related to unsatisfactory preparation of the nurses in their undergraduate studying, the review of nursing curriculum showed that chemotherapy extravasation did not cover, moreover, many nursing curriculum did not cover oncology nursing course for the undergraduate students. Furthermore, lacking of staff development, and continue education could be the reasons for these results. In the current study, $94.6 \%$ of the participants stated that they did not receive continue education program about extravasation among patients with cancer. Failure to identify risk factors can affect the quality of nursing care, increasing incidence of chemotherapy extravasation, affecting the treatment plan. ${ }^{10}$ These results is not unique to the oncology nurses, similar findings were reported in Brazil and the nurses showed lack of knowledge in relation to risk factors for extravasation. ${ }^{15}$

Knowledge of preventive strategies was divided into three elements according to ESMO- EONS guidelines including site of insertion, cannula characteristics, and the procedure. Limited knowledge was reported by the nurses regarding site of insertion and cannula characteristics. The study enumerated that $74.5 \%$ of the nurses did not know that veins in anticubital fossa or on the dorsum of the hand should be avoided, and more than $75 \%$ the nurses had incorrect conception about butterfly cannula, flexible cannula, and usage of central venous access for period of infusion longer than 12-24 h. In the opposite, the results showed that nurses were highly knowledgeable in relation to the procedure itself. They had excellent knowledge about cannulation, assessment, and infusion as shown in Table 3. These findings are not surprising, as the nurses were prepared during their undergraduate study how to perform cannulation and assessment, but, related to cannula characteristics and site of insertion to prevent extravasation; they had limited knowledge as they did not receive education about this. These results highlighted the importance of continue education in improving nurses' knowledge and strengthening their competencies. In this regard, a descriptive study that conducted by Kosgeroglu et al. showed that nurses knowledge about chemotherapy administration was insufficient in Turkey. ${ }^{16}$

Alarmingly, the results from the current study revealed that the participants' knowledge about recent evidence-based management practices for extravasation was very limited especially in relation to specific treatment and general measures elements also. According to ESMO- EONS guidelines, there is specific intervention for extravasation based on the chemotherapy types. Nurses' knowledge about these evidence-based interventions was insufficient and indicated that their knowledge was outdated and should be improved. The review of the previous literature revealed that there is no study conducted to evaluate the nurses' knowledge about management practices for extravasation. The current study's results added to the previous literature and highlighted the need to prepare qualified nurses able to provide safe care.

Moreover, the results of the current study highlighted the importance of continuing education to maintain oncology nursing staff with updated evidence-based knowledge and practices. Continues improvement of nurses knowledge about extravasation preventions and megamenu should be in top priorities. In addition, extravasation protocol should be updated, and nurses; adherence to the evidence-based practices has to be evaluated frequently. Nursing researchers can determine barriers for nonadherence among the oncology nurses.

Despite of the interesting and valuable results, the current study has some limitations including that the current study's results was based on perceived evaluation of the current practice, future research with observation technique is recommended. The current study focused on nurses only, assessing other health professional's knowledge such as pharmacists is recommended.

\section{Conclusion}

Importantly, the current study provides a baseline data about oncology nurses knowledge and practice regarding extravasation care. 
Alarmingly, nurses' knowledge about management practices was inadequate. This might affect the quality of care provided to the patients with extravasation. Continues education, seminars, and workshops should be conducted for oncology nurses. Clear policy, updated evidence-based guidelines, and written instruction should be used to increase nurses; knowledge and strengthen their competencies.

\section{Compliance with ethical standards}

\section{Ethical compliance}

Institutional Review Board approval was obtained.

\section{Conflict of interest}

The author declares that they have no conflict of interest.

\section{Funding}

This research did not receive any specific grant from funding agencies in the public, commercial, or not-for-profit sectors.

\section{Acknowledgement}

The author would like to thank the participants for their effort and time.

\section{References}

1. Ferlay J, Soerjomataram I, Dikshit R, et al. Cancer incidence and mortality worldwide: sources, methods and major patterns in GLOBOCAN 2012. Int J Canc.
2015;136(5):E359-E386.

2. Al Qadire M, Al Khalaileh M. Prevalence of symptoms and quality of life among Jordanian cancer patients. Clin Nurs Res. 2016;25(2):174-191.

3. Wu H-S, Davis JE, Chen L. Impact of Comorbidity on Symptoms and Quality of Life Among Patients Being Treated for Breast Cancer. Cancer Nursing; 2018.

4. Coyle CE, Griffie J, Czaplewski LM. Eliminating extravasation events: a multidisciplinary approach. J Infusion Nurs: Off Publ Infusion Nurses Society. 2015;38:S43-S50.

5. Robinson A, Souied O, Bota AB, et al. Optimal vascular access strategies for patients receiving chemotherapy for early-stage breast cancer: a systematic review. Breast Canc Res Treat. 2018;171(3):607-620.

6. Somayaji S, Reddy S, Murthy MK. Extent of extravasation injury among patients receiving parenteral chemotherapy. Value Health. 2018;21:S20.

7. Lapeyre-Prost A, de Larauze MH, Chibaudel B, et al. Feasibility of capecitabine and oxaliplatin combination chemotherapy without central venous access device in patients with stage III colorectal cancer. Clin Colorectal Canc. 2016;15(3):250-256.

8. Biswal SG, Mehta RD. Cutaneous adverse reactions of chemotherapy in cancer patients: a clinicoepidemiological study. Indian J Dermatol. 2018;63(1):41.

9. Kimmel J, Fleming P, Cuellar S, Anderson J, Haaf CM. Pharmacological management of anticancer agent extravasation: a single institutional guideline. J Oncol Pharm Pract. 2018;24(2):129-138.

10. Agbessi O, Arrob A, N'diaye A, Sabani H, Karim M. Extended arm necrosis by chemotherapy drugs extravasation. Chemother Open Access Infus Nurs Soc. 2015;4(147):2

11. Le A, Patel S. Extravasation of noncytotoxic drugs: a review of the literature. Ann Pharmacother. 2014;48(7):870-886.

12. Faul F, Erdfelder E, Lang A-G, Buchner AG. * Power 3: a flexible statistical power analysis program for the social, behavioral, and biomedical sciences. Behav Res Methods. 2007;39(2):175-191.

13. Perez Fidalgo J, García Fabregat L, Cervantes A, Margulies A, Vidall C, Roila F. Management of chemotherapy extravasation: ESMO-EONS clinical practice guidelines. Ann Oncol. 2012;23(suppl_7):vii167-v173.

14. Gibson F, Shipway L, Aldiss S, et al. Exploring the work of nurses who administer chemotherapy to children and young people. Eur J Oncol Nurs. 2013;17(1):59-69.

15. Gozzo TdO, Santos LAC, Cruz LAPd. Knowledge of the nursing team on the prevention and management of extravasation of chemotherapy drugs. J Nurs UFPE Line. 2017;11(12):4789-4797.

16. Kosgeroglu N, Ayranci U, Ozerdogan N, Demirustu C. Turkish nurses' information about, and administration of, chemotherapeutic drugs. J Clin Nurs. 2006;15(9):1179-1187. 